\title{
Physical Activity, Health Status and Risk of Hospitalization in Patients with Severe Chronic Obstructive Pulmonary Disease
}

\author{
Roberto P. Benzo ${ }^{a}$ Chung-Chou H. Chang ${ }^{b, c}$ Max H. Farrell ${ }^{b}$ Robert Kaplan $^{d}$ \\ Andrew Ries ${ }^{\mathrm{e}}$ Fernando J. Martinez ${ }^{f}$ Robert Wise ${ }^{g} \quad$ Barry Make $^{\mathrm{h}}$ \\ Frank Sciurba ${ }^{i}$ for the NETT Research Group \\ ${ }^{a}$ Division of Pulmonary and Critical Care Medicine, Department of Medicine, Mayo Clinic, Rochester, Minn., \\ ${ }^{\mathrm{b}}$ Division of General Internal Medicine, Department of Medicine, School of Medicine, and 'Department of

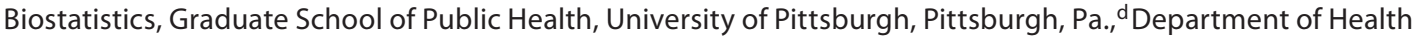 \\ Services, University of California, Los Angeles, Calif., ' Department of Medicine and Family and Preventive

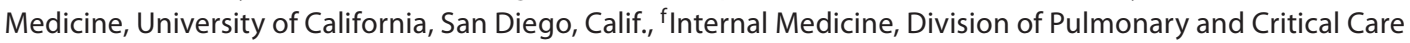 \\ Medicine, University of Michigan, Ann Arbor, Mich., ${ }^{9}$ Division of Pulmonary and Critical Care Medicine, Johns \\ Hopkins University, Baltimore, Md., h Division of Pulmonary Sciences, National Jewish Medical Center and Research \\ Center, Denver, Colo., and 'Division of Pulmonary and Critical Care Medicine, Department of Medicine, School of \\ Medicine, University of Pittsburgh, Pittsburgh, Pa., USA
}

For editorial comment see p. 8

\section{Key Words}

Activity of daily living - Chronic obstructive pulmonary disease $\cdot$ Emphysema $\cdot$ Outcomes $\cdot$ Quality of life $\cdot$ Health status $\cdot$ Exercise

\begin{abstract}
Background: Chronic obstructive pulmonary disease (COPD) is a leading cause of death and $70 \%$ of the cost of COPD is due to hospitalizations. Self-reported daily physical activity and health status have been reported as predictors of a hospitalization in COPD but are not routinely assessed. Objectives: We tested the hypothesis that self-reported daily physical activity and health status assessed by a simple question were predictors of a hospitalization in a well-characterized cohort of patients with severe emphysema. Methods: Inves-
\end{abstract}

tigators gathered daily physical activity and health status data assessed by a simple question in 597 patients with severe emphysema and tested the association of those patient-reported outcomes to the occurrence of a hospitalization in the following year. Multiple logistic regression analyses were used to determine predictors of hospitalization during the first 12 months after randomization. Results: The two variables tested in the hypothesis were significant predictors of a hospitalization after adjusting for all univariable significant predictors: $>2 \mathrm{~h}$ of physical activity per week had a protective effect [odds ratio (OR) $0.60 ; 95 \%$ confidence interval $(95 \% \mathrm{Cl}) 0.41-0.88$ ] and self-reported health status as fair or poor had a deleterious effect (OR 1.57; 95\% Cl 1.102.23). In addition, two other variables became significant in the multivariate model: total lung capacity (every $10 \%$ increase) had a protective effect (OR 0.88; $95 \% \mathrm{Cl} 0.78-0.99$ )

\section{KARGER}

๑) 2010 S. Karger AG, Basel

Fax +4161306 1234

E-Mail karger@karger.ch

www.karger.com
Accessible online at:

www.karger.com/res
Roberto P. Benzo, MD, MSc

Division of Pulmonary and Critical Care Medicine, Mayo Clinic

200 First St. SW

Rochester, MN 55905 (USA)

Tel. +1 507284 3764, Fax +1 507266 4372, E-Mail benzo.roberto@ mayo.edu 
and self-reported anxiety had a deleterious effect (OR 1.75; $95 \% \mathrm{Cl} 1.13-2.70)$. Conclusion: Self-reported daily physical activity and health status are independently associated with COPD hospitalizations. Our findings, assessed by simple questions, suggest the value of patient-reported outcomes in developing risk assessment tools that are easy to use.

Copyright $\odot 2010$ S. Karger AG, Basel

\section{Introduction}

Chronic obstructive pulmonary disease (COPD) is a frequent cause of hospitalization [1] and is the fourth leading cause of death in the United States [2]. Hospitalizations not only have a negative impact on the well-being, lung function, and survival rates for patients with COPD, but they also account for $70 \%$ of the treatment costs for this disease [3-6]. The development of new instruments to identify risk factors for hospitalization is important because these instruments can help health care providers create and apply appropriate and timely interventions to prevent a hospital admission. The ideal instrument would focus on significant predictive factors to identify patients at high risk for hospitalization by means of a short list of questions since a simple instrument would be more likely to translate into everyday use in clinical practice.

Measures that have started to be more prevalent in the COPD literature are daily physical activity and health status. Self-reported physical activity was reported in a large cohort of patients with COPD to be an independent predictor of hospitalization and mortality [7]. In addition, daily physical activity is associated with a lower decline in lung function in COPD patients [8]. Health status has been associated with an increased risk of hospitalization in COPD patients [9-12]. Importantly, physical activity and health status are potentially modifiable risk factors.

Our study was designed to determine whether those factors were associated with increased rates of hospitalization in a large, prospective cohort of well-characterized patients with severe COPD [13], the National Emphysema Treatment Trial (NETT).

\section{Methods}

\section{Database}

The data for our analysis were derived from NETT, a randomized controlled trial that involved patients from 17 clinics in various regions of the United States [13]. The design and methods of the trial have been published elsewhere [13-15]. Between January 1998 and July 2002, the NETT investigators enrolled patients who had emphysema, severe airflow limitation, and a forced expiratory volume in $1 \mathrm{~s}\left(\mathrm{FEV}_{1}\right)$ of $45 \%$ of predicted or lower.

The patients completed $6-10$ weeks of pulmonary rehabilitation and provided baseline sociodemographic, clinical, and quality-of-life data before they were randomized to receive continued medical treatment or lung volume reduction surgery. The primary outcome measures were mortality and maximum exercise capacity 2 years after randomization.

Our analysis focused on the 610 patients who were randomized to the medical arm, and our primary outcome was hospitalization during the 12-month period after randomization. The information on hospitalizations was based on self-report from patients who completed scripted questionnaires at 1 and 2 months after randomization and every 2 months thereafter in face-to-face encounters or via the telephone.

The multisite trial was approved by the institutional review board at each site, and all patients involved in the trial provided written informed consent. Our analysis was considered exempt from the need for additional consent.

\section{Collection and Processing of Data}

For the evaluation of physical activity, patients were asked how many days during the previous week they performed lower-extremity endurance exercises, such as walking or cycling, and for how many minutes each day. The value of daily physical activity used in the analysis was the average of interviews at 1 and 2 months after randomization. That averaged value was used as a proxy for randomization time information. The rationale for using an average of 2 months was twofold: first, the questions used are not psychometrically tested (with test-retest reliability) as there is no validated COPD activity questionnaire, and second the reliability analysis of the activity questions at month 1 versus month 2 showed a moderate intraclass correlation coefficient of 0.64 - cutoff value recommended for a reliable item is 0.7 . For the above reasons, the authors believed that the average provided a much more robust indicator of physical activity.

We analyzed self-reported physical activity as a continuous variable (number of minutes exercised per week: obtained from how many days per week they reported activity•activity duration, minutes, reported) and as a dichotomous variable (physical activity $<2 \mathrm{~h}$ a week vs. $\geq 2 \mathrm{~h}$ a week). We used the cutoff of $2 \mathrm{~h}$ per week because it was found to be significant in a previous study of a large cohort of patients with severe COPD [7].

Information about depression was obtained prior to randomization from responses to the Beck Depression Inventory, a 21item instrument with total score that ranges from 0 to 63. A total score of 10 or higher is consistent with mild to moderate depressive symptoms $[16,17]$ and is associated with the risk of adverse outcomes in several medical conditions $[18,19]$. We used this score as a cutoff for the presence or absence of depressive symptoms. However, for purposes of comparison, we also used a score of $>15$ as a cutoff. Information about anxiety was obtained prior to randomization from the responses of patients to the item in the Quality of Well-Being Scale that queries excessive worry or anxiety in the past 3 days. The response options from the tool were: 'no days, yesterday, 2 days ago and 3 days ago'. For the purpose of the analysis, the responses were grouped as 'no days' or 'at least one day'. 
Table 1. Sociodemographic and clinical characteristics of patients at baseline ${ }^{1}$

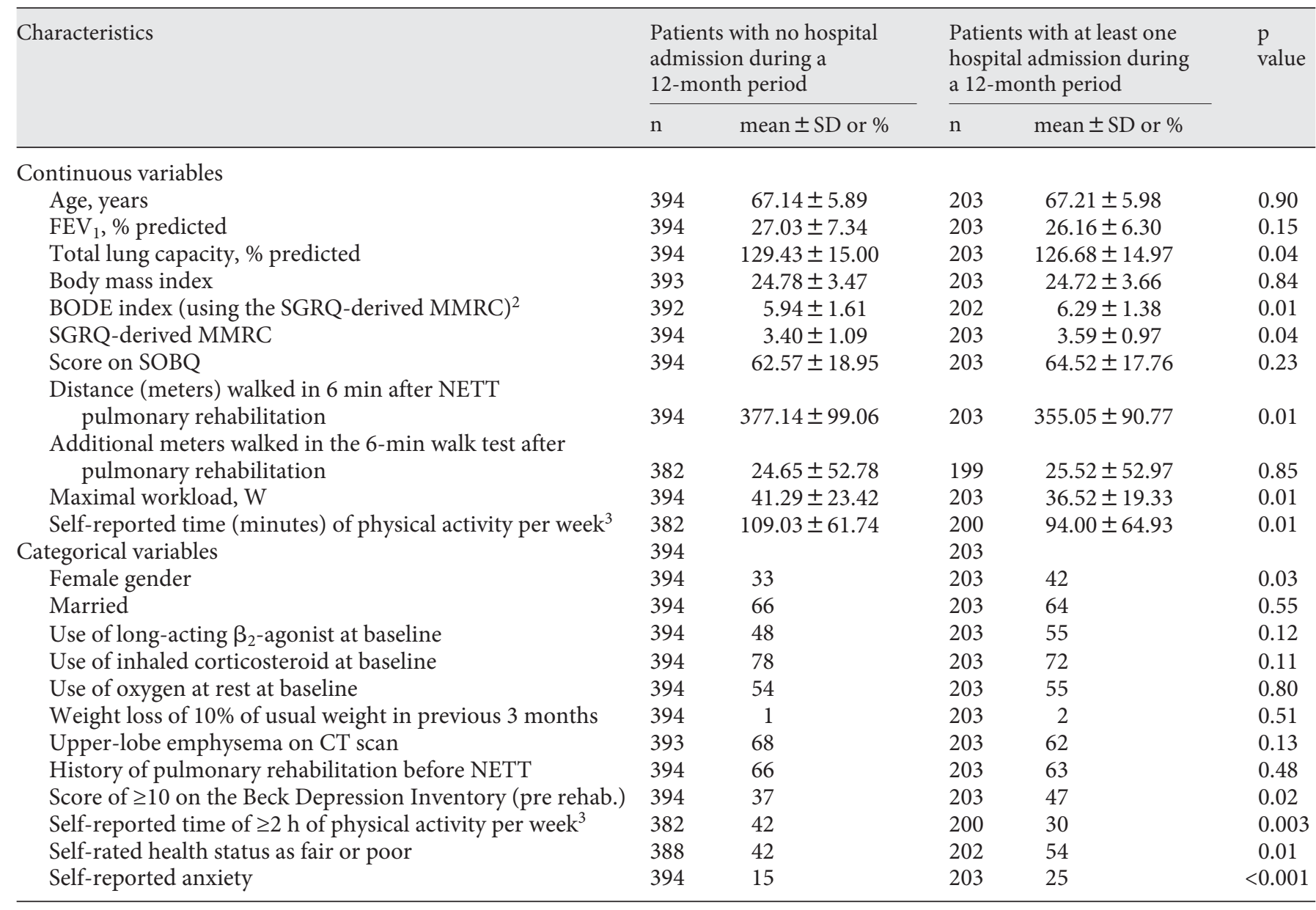

$\mathrm{CT}=$ Computed tomography; MRC = Medical Research Council; SD = standard deviation; SOBQ = University of California-San Diego Shortness of Breath Questionnaire.

${ }^{1}$ Post Pulmonary Rehabilitation. The outcome of interest was hospital admissions during the 12-month period after randomization in the study. $\mathrm{p}$ values are for univariable logistic regression analyses.

${ }^{2}$ See Method section for full explanation of the SGRQ-derived MMRC.

${ }^{3}$ This measure comes from the average between the first and second month after randomization.

In addition to including these self-reported items in our analysis, we included baseline information concerning the sociodemographic and clinical characteristics shown in table 1.

\section{Statistical Analyses}

For analysis purpose, we divided the patients into two groups, one with no hospital admissions and the other with at least 1 hospital admission in the first 12 months after randomization. We used descriptive statistics to report the numbers and percentages of patients having each of the sociodemographic, clinical, and other characteristics of interest. To determine the association between each variable and hospitalization, we used univariable logistic regression analyses. If a variable had a $\mathrm{p}<0.1$ in univariable analyses, we included it in the multiple logistic regression model to predict the odds of hospitalization. To determine the strength of association between physical activity (self-reported), the 6-min walk test, and the maximum workload test, we used the Pearson correlation coefficient. Analysis was completed using Stata version 9 (StataCorp, College Station, Tex., USA) and considered $\mathrm{p}<0.05$ to be significant.

\section{Results}

Of 610 patients in the medical arm of NETT, 597 (96\%) had complete information about hospitalization. The baseline characteristics of patients with and without at 
Table 2. Predictors of hospitalization based on multiple logistic regression $^{1}$

\begin{tabular}{|c|c|c|}
\hline Predictor & Odds ratio & $\mathrm{p}$ value \\
\hline \multicolumn{3}{|l|}{$\begin{array}{l}\text { Total lung capacity, } \% \text { predicted } \\
\text { (every } 10 \% \text { increase) }\end{array}$} \\
\hline $\begin{array}{l}\text { Self-reported time of } \geq 2 \mathrm{~h} \text { of } \\
\text { physical activity per week }\end{array}$ & $0.60(0.41-0.88)$ & 0.01 \\
\hline $\begin{array}{l}\text { Self-rated health status as fair or } \\
\text { poor versus good, very good, } \\
\text { or excellent (from SF-36 tool) }\end{array}$ & $1.57(1.10-2.23)$ & 0.01 \\
\hline $\begin{array}{l}\text { Self-reported anxiety } \\
\quad \text { (from quality of well-being tool) }\end{array}$ & $1.75(1.13-2.70)$ & 0.01 \\
\hline \multicolumn{3}{|c|}{$\begin{array}{l}95 \% \text { CI are shown in parentheses. } \\
1 \text { The variables included in the multiple logistic regression } \\
\text { model were the ones that were univariable significant at the } 0.1 \\
\text { level or less (table } 1 \text { ). The area under the receiver operating char- } \\
\text { acteristic curve for this model was } 0.63 \text {. }\end{array}$} \\
\hline
\end{tabular}

least 1 hospital admission during the first 12 months of the study are shown in table 1.

In univariable analyses, the following characteristics were associated with hospitalization: gender, total lung capacity percent predicted, BODE index (body mass index, airflow obstruction, functional dyspnea, exercise capacity), the MMRC Dyspnea Scale, distance (meters) walked in 6 min after the NETT pulmonary rehabilitation, self-reported time (minutes) of physical activity per week, a score equal or higher than 10 on the Beck Depression Inventory, self-reported time of $\geq 2 \mathrm{~h}$ of physical activity per week, self-rated health status as fair or poor (as opposed to 'good, very good or excellent'), and self-reported anxiety. These variables were included in the multiple logistic regression model.

In the multiple logistic regression model (table 2), only four variables were significant predictors of a hospitalization after adjusting for all univariable significant predictors: two were protective, self-report of $\geq 2 \mathrm{~h}$ of physical activity per week [odds ratio (OR) $0.60 ; 95 \%$ confidence interval (95\% CI) $0.41-0.88$ ) and total lung capacity (every $10 \%$ increase)- (OR 0.88 ; $95 \%$ CI $0.78-0.99$ ), and two variables increased the risk: self-reported health status as fair or poor (OR 1.57; 95\% CI 1.10-2.23) and self-reported anxiety (OR 1.75; 95\% CI 1.13-2.70). The area under the receiver operating characteristic curve for the multiple logistic regression model was 0.65 .
Although the continuous variable for physical activity displayed a low correlation with exercise capacity defined by the 6 -min walk test $(R=0.2)$ and a low correlation with the maximum workload test on the cycle ergometer $(\mathrm{R}=$ $0.2)$, the correlations were significant $(\mathrm{p}<0.05$ for each) because of the large sample size. The correlations between the distance walked in 6 min and the maximum workload were stronger $(\mathrm{R}=0.6 ; \mathrm{p}<0.001)$, but neither of these measures was found to be a predictor of hospitalization.

On the Beck Depression Inventory, a score $\geq 10$ was not associated with hospitalization. Nor was a score of $>15$ associated with hospitalization but showed a trend toward statistical significance (OR 1.5; 95\% CI 0.96-2.84; $\mathrm{p}=0.07)$.

The BODE index, used as a continuous variable, was not associated with hospitalization.

\section{Discussion}

In our analysis of data from patients involved in the medical arm of the NETT, we found and confirmed our hypothesis that self-reported daily physical activity, health status and anxiety are predictors of a hospital admission in patients with severe emphysema. Remarkably, each of those important predictors was easily and rapidly assessed by asking simple questions. We definitively confirmed previous data suggesting that the self-report of health status using question 1 of the SF-36 ('Do you rate your health as excellent, very good, good, fair or poor?') and total lung capacity are associated with hospitalization as previously reported $[10,14]$.

We believe our results on daily physical activity are of great significance for risk assessment of severe COPD and emphasize the need to include the assessment of physical activity in clinical trials and daily practice. Physical activity is a potentially modifiable risk factor to assess that can be impacted by interventions like pulmonary rehabilitation, or by a comprehensive self-management or integrated care programs for COPD. Maintaining longterm physical activity is a desired goal of pulmonary rehabilitation that has not yet been attained. Our findings on physical activity raise interesting questions about the construct. The correlations between self-reported physical activity and results in exercise capacity tests (maximum workload and 6-min walk) were only modest. In the multivariate model, only self-reported physical activity - but none of the measures of exercise capacity - was a predictor of hospitalization. These findings suggest that 
exercise capacity and reported physical activity provide different information and that the two measures might actually be different constructs. Furthermore, it is plausible that the level of actual physical activity depends on the patient's mood and/or perception of his or her health.

We found that the odds of being hospitalized are about 1.6 times as great in patients who rate their health as fair or poor. The latter seems a very intuitive finding, but it is remarkable that some patients with severe emphysema did perceive their health as 'good' or even 'very good' and suggests about the profound effect that a positive perception of health can have to avoid hospitalization. Previous studies using the same simple first question from the SF36 questionnaire [10] or other tools $[11,20]$ have linked self-reported health status with hospitalizations, health system utilization and mortality.

We also found that the odds of being hospitalized are about 1.7 times as great in patients who endorse a single item about anxiety. To our knowledge, this is the first report of an association between hospitalization and anxiety measured with a single question answered by patients with COPD. Our results are consistent with a previous report that found an association between rehospitalization and anxiety that used the Hospital Anxiety and Depression Scale [9] as a tool but contrast with another analysis of NETT data that found no association between hospital admission and anxiety using the State-Trait Anxiety Inventory [21]. It is likely that the specific instrument used to evaluate anxiety may have a significant impact in explaining the findings across studies. The use of behavioral interventions in severe COPD that may reduce anxiety may be a significant research question to test, given our results and the positive results of behavioral interventions in other chronic diseases, such as diabetes [22-24]. It is unknown whether treatment of anxiety symptoms would reduce the risk of hospitalization in patients with severe COPD.

In our study, a score $\geq 10$ on the Beck Depression Inventory was associated with hospitalization in univariable analysis, but neither a score of $\geq 10$ nor a score of $>15$ was associated with hospitalization in multiple regression analysis. These findings are consistent with the results of a study of depression and COPD-related hospitalizations by Fan et al. [21]. Although depressive symptoms are a potentially modifiable risk factor, Fan et al. [21] found that the use of antidepressants did not reduce the risk of COPD-related hospitalization when their models were adjusted for meaningful covariates. However, they were unable to ascertain the dosage of or compliance with therapy. Studies are needed to test the benefit of a combi- nation of behavioral and pharmacologic interventions for depressive symptoms in these patients.

Our finding on hyperinflation as a protective factor seems to be counterintuitive. We speculate that less hyperinflation may indicate restriction coming from comorbidities like pulmonary hypertension or undetected heart failure that are prevalent in this population of patients with severe emphysema.

The BODE index is an unquestionable predictor of mortality $[14,25,26]$, but it was not significant in predicting hospitalization in our analysis. While a previous study found that the BODE index was a significant predictor of the number of hospitalizations [27], the results were somewhat unclear since patients with BODE scores of 5 or 6 (scale $0-10$ : 0 being the best and 10 being the worst scores) were less likely to require hospitalization than those with BODE scores of $0-2$.

In our model, hospitalization is mainly explained by 3 self-reported predictors (physical activity, health status perception and anxiety), suggesting that patients' perceptions are as important or even more important as structural variables in determining a hospitalization.

Our analysis of the self-reported physical activity, anxiety and health status builds on the work of previous studies $[7,9,10]$ but extends previous findings to a wellcharacterized group of patients with severe COPD. It also contributes to the goal of developing effective and parsimonious risk assessment tools.

Several limitations and strengths of our study deserve mention. Because our results are based on the analysis of a sample of patients with severe COPD, the results may have limited generalizability to patients with mild COPD. However, hospitalizations occur with higher frequency in patients with severe disease [28]. Our prediction model explained $65 \%$ of the variance of hospitalization, and this allows us to report a strong association but not to create a prediction tool. Our measure of anxiety, coming from a single item from the Quality of Well-Being Questionnaire, is not a standardized measure of anxiety and requires further testing to determine the soundness of the measure.

The strength of our study lies in the fact that the NETT data set had few missing values for the variables and outcome of interest in our analysis. The use of scripted questionnaires during telephone calls or face-to-face encounters to assess hospital admissions every 2 months makes the possibility of recall bias or information bias unlikely. Our results on hospitalizations are consistent with those reported by another group of investigators who used the same dataset but assessed hospitalization from health re- 
cords [21], suggesting the robustness of our assessment of the primary outcome (hospitalization).

Our results highlight the importance of assessing daily physical activity and health status to predict a hospital admission. The latter appears to be mainly determined by factors related to patient's perceptions of health, physical activity and emotions, which often tend to be considered as 'soft' parameters.

Our findings also suggest that a simple assessment of those parameters will help clinicians to identify patients with COPD at higher risk. A rapid identification may trigger the initiation of more comprehensive treatments in patients who are at higher risk of hospitalization, such as intensive pulmonary rehabilitation with self-management or integrated care programs for COPD [29-31].

In an era when patient self-reports are often disregarded, it is noteworthy that these simple reports that are easily obtained might offer valuable information for risk assessment and decision making.

\section{Appendix}

\section{Members of the NETT Research Group}

Office of the Chair of the Steering Committee, University of Pennsylvania, Philadelphia, Pa., USA: Alfred P. Fishman, MD (Chair); Betsy Ann Bozzarello; Ameena Al-Amin.

Baylor College of Medicine, Houston, Tex., USA: Marcia Katz, MD (Principal Investigator); Carolyn Wheeler, RN, BSN (Principal Clinic Coordinator); Elaine Baker, RRT, RPFT; Peter Barnard, PhD, RPFT; Phil Cagle, MD; James Carter, MD; Sophia Chatziioannou, MD; Karla Conejo-Gonzales; Kimberly Dubose, RRT; John Haddad, MD; David Hicks, RRT, RPFT; Neal Kleiman, MD; Mary Milburn-Barnes, CRTT; Chinh Nguyen, RPFT; Michael Reardon, MD; Joseph Reeves-Viets, MD; Steven Sax, MD; Amir Sharafkhaneh, MD; Owen Wilson, PhD; Christine Young PT; Rafael Espada, MD (Principal Investigator 1996-2002); Rose Butanda (1999-2001); Minnie Ellisor (2002); Pamela Fox, MD (19992001); Katherine Hale, MD (1998-2000); Everett Hood, RPFT (1998 ( 2000); Amy Jahn (1998-2000); Satish Jhingran, MD (1998-2001); Karen King, RPFT (1998-1999); Charles Miller III, PhD (1996-1999); Imran Nizami, MD (Co-Principal Investigator, 2000-2001); Todd Officer (1998-2000); Jeannie Ricketts (1998 -2000); Joe Rodarte, MD (Co-Principal Investigator 1996-2000); Robert Teague, MD (Co-Principal Investigator 1999-2000); Kedren Williams (1998-1999).

Brigham and Women's Hospital, Boston, Mass., USA: John Reilly, MD (Principal Investigator); David Sugarbaker, MD (CoPrincipal Investigator); Carol Fanning, RRT (Principal Clinic Coordinator); Simon Body, MD; Sabine Duffy, MD; Vladmir Formanek, MD; Anne Fuhlbrigge, MD; Philip Hartigan, MD; Sarah Hooper, EP; Andetta Hunsaker, MD; Francine Jacobson, MD; Marilyn Moy, MD; Susan Peterson, RRT; Roger Russell, MD; Diane Saunders; Scott Swanson, MD (Co-Principal Investigator, 1996-2001).

Risk of Hospitalization in COPD
Cedars-Sinai Medical Center, Los Angeles, Calif., USA: Rob McKenna, MD (Principal Investigator); Zab Mohsenifar, MD (Co-Principal Investigator); Carol Geaga, RN (Principal Clinic Coordinator); Manmohan Biring, MD; Susan Clark, RN, MN; Jennifer Cutler, MD; Robert Frantz, MD; Peter Julien, MD; Michael Lewis, MD; Jennifer Minkoff-Rau, MSW; Valentina Yegyan, BS, CPFT; Milton Joyner, BA (1996-2002).

Cleveland Clinic Foundation, Cleveland, Ohio, USA: Malcolm DeCamp, MD (Principal Investigator); James Stoller, MD (CoPrincipal Investigator); Yvonne Meli, RN,C (Principal Clinic Coordinator); John Apostolakis, MD; Darryl Atwell, MD; Jeffrey Chapman, MD; Pierre DeVilliers, MD; Raed Dweik, MD; Erik Kraenzler, MD; Rosemary Lann, LISW; Nancy Kurokawa, RRT, CPFT; Scott Marlow, RRT; Kevin McCarthy, RCPT; Priscilla McCreight, RRT, CPFT; Atul Mehta, MD; Moulay Meziane, MD; Omar Minai, MD; Mindi Steiger, RRT; Kenneth White, RPFT; Janet Maurer, MD (Principal Investigator, 1996-2001); Terri Durr, RN (2000-2001); Charles Hearn, DO (1998-2001); Susan Lubell, PA-C (1999-2000); Peter O’Donovan, MD (1998-2003); Robert Schilz, DO (1998-2002).

Columbia University, New York, NY in consortium with Long Island Jewish Medical Center, New Hyde Park, N.Y., USA: Mark Ginsburg, MD (Principal Investigator); Byron Thomashow, MD (Co-Principal Investigator); Patricia Jellen, MSN, RN (Principal Clinic Coordinator); John Austin, MD; Matthew Bartels, MD; Yahya Berkmen, MD; Patricia Berkoski, MS, RRT (Site coordinator, LIJ); Frances Brogan, MSN, RN; Amy Chong, BS, CRT; Glenda DeMercado, BSN; Angela DiMango, MD; Sandy Do, MS, PT; Bessie Kachulis, MD; Arfa Khan, MD; Berend Mets, MD; Mitchell O(Shea, BS, RT, CPFT; Gregory Pearson, MD; Leonard Rossoff, MD; Steven Scharf, MD, PhD (Co-Principal Investigator, 19982002); Maria Shiau, MD; Paul Simonelli, MD; Kim Stavrolakes, MS, PT; Donna Tsang, BS; Denise Vilotijevic, MS, PT; Chun Yip, MD; Mike Mantinaos, MD (1998-2001); Kerri McKeon, BS, RRT, RN (1998-1999); Jacqueline Pfeffer, MPH, PT (1997-2002).

Duke University Medical Center, Durham, N.C., USA: Neil MacIntyre, MD (Principal Investigator); R. Duane Davis, MD (Co-Principal Investigator); John Howe, RN (Principal Clinic Coordinator); R. Edward Coleman, MD; Rebecca Crouch, RPT; Dora Greene; Katherine Grichnik, MD; David Harpole, Jr., MD; Abby Krichman, RRT; Brian Lawlor, RRT; Holman McAdams, MD; John Plankeel, MD; Susan Rinaldo-Gallo, MED; Sheila Shearer, RRT; Jeanne Smith, ACSW; Mark Stafford-Smith, MD; Victor Tapson, MD; Mark Steele, MD (1998-1999); Jennifer Norten, MD (1998-1999).

Mayo Foundation, Rochester, Minn., USA: James Utz, MD (Principal Investigator); Claude Deschamps, MD (Co-Principal Investigator); Kathy Mieras, CCRP (Principal Clinic Coordinator); Martin Abel, MD; Mark Allen, MD; Deb Andrist, RN; Gregory Aughenbaugh, MD; Sharon Bendel, RN; Eric Edell, MD; Marlene Edgar; Bonnie Edwards; Beth Elliot, MD; James Garrett, RRT; Delmar Gillespie, MD; Judd Gurney, MD; Boleyn Hammel; Karen Hanson, RRT; Lori Hanson, RRT; Gordon Harms, MD; June Hart; Thomas Hartman, MD; Robert Hyatt, MD; Eric Jensen, MD; Nicole Jenson, RRT; Sanjay Kalra, MD; Philip Karsell, MD; Jennifer Lamb; David Midthun, MD; Carl Mottram, RRT; Stephen Swensen, MD; Anne-Marie Sykes, MD; Karen Taylor; Norman Torres, MD; Rolf Hubmayr, MD (1998-2000); Daniel Miller, MD (1999-2002); Sara Bartling, RN (1998-2000); Kris Bradt (1998-2002). 
National Jewish Medical and Research Center, Denver, Colo., USA: Barry Make, MD (Principal Investigator); Marvin Pomerantz, MD (Co-Principal Investigator); Mary Gilmartin, RN, RRT (Principal Clinic Coordinator); Joyce Canterbury; Martin Carlos; Phyllis Dibbern, PT; Enrique Fernandez, MD; Lisa Geyman, MSPT; Connie Hudson; David Lynch, MD; John Newell, MD; Robert Quaife, MD; Jennifer Propst, RN; Cynthia Raymond, MS; Jane Whalen-Price, PT; Kathy Winner, OTR; Martin Zamora, MD; Reuben Cherniack, MD (Principal Investigator, 1997-2000).

Ohio State University, Columbus, Ohio, USA: Philip Diaz, MD (Principal Investigator); Patrick Ross, MD (Co-Principal Investigator); Tina Bees (Principal Clinic Coordinator); Jan Drake; Charles Emery, PhD; Mark Gerhardt, MD, PhD; Mark King, MD; David Rittinger; Mahasti Rittinger.

Saint Louis University, Saint Louis, Mo., USA: Keith Naunheim, MD (Principal Investigator); Robert Gerber, MD (Co-Principal Investigator); Joan Osterloh, RN, MSN (Principal Clinic Coordinator); Susan Borosh; Willard Chamberlain, DO; Sally Frese; Alan Hibbit; Mary Ellen Kleinhenz, MD; Gregg Ruppel; Cary Stolar, MD; Janice Willey; Francisco Alvarez, MD (Co-Principal Investigator, 1999-2002); Cesar Keller, MD (Co-Principal Investigator, 1996-2000).

Temple University, Philadelphia, Pa., USA: Gerard Criner, MD (Principal Investigator); Satoshi Furukawa, MD (Co-Principal Investigator); Anne Marie Kuzma, RN, MSN (Principal Clinic Coordinator); Roger Barnette, MD; Neil Brister, MD; Kevin Carney, RN, CCTC; Wissam Chatila, MD; Francis Cordova, MD; Gilbert D’Alonzo, DO; Michael Keresztury, MD; Karen Kirsch; Chul Kwak, MD; Kathy Lautensack, RN, BSN; Madelina Lorenzon, CPFT; Ubaldo Martin, MD; Peter Rising, MS; Scott Schartel, MD; John Travaline, MD; Gwendolyn Vance, RN, CCTC; Phillip Boiselle, MD (1997-2000); Gerald O'Brien, MD (1997-2000).

University of California, San Diego, San Diego, Calif., USA: Andrew Ries, MD, MPH (Principal Investigator); Robert Kaplan, $\mathrm{PhD}$ (Co-Principal Investigator); Catherine Ramirez, BS, RCP (Principal Clinic Coordinator); David Frankville, MD; Paul Friedman, MD; James Harrell, MD; Jeffery Johnson; David Kapelanski, MD; David Kupferberg, MD, MPH; Catherine Larsen, MPH; Trina Limberg, RRT; Michael Magliocca, RN, CNP; Frank J. Papatheofanis, MD, PhD; Dawn Sassi-Dambron, RN; Melissa Weeks.

University of Maryland at Baltimore, Baltimore, $M d$. in consortium with Johns Hopkins Hospital, Baltimore, Md., USA: Mark Krasna, MD (Principal Investigator); Henry Fessler, MD (CoPrincipal Investigator); Iris Moskowitz (Principal Clinic Coordinator); Timothy Gilbert, MD; Jonathan Orens, MD; Steven Scharf, MD, PhD; David Shade; Stanley Siegelman, MD; Kenneth Silver, MD; Clarence Weir; Charles White, MD.

University of Michigan, Ann Arbor, Mich., USA: Fernando Martinez, MD (Principal Investigator); Mark Iannettoni, MD (Co-Principal Investigator); Catherine Meldrum, BSN, RN, CCRN (Principal Clinic Coordinator); William Bria, MD; Kelly Campbell; Paul Christensen, MD; Kevin Flaherty, MD; Steven Gay, MD; Paramjit Gill, RN; Paul Kazanjian, MD; Ella Kazerooni, MD; Vivian Knieper; Tammy Ojo, MD; Lewis Poole; Leslie Quint, MD; Paul Rysso; Thomas Sisson, MD; Mercedes True; Brian Woodcock, MD; Lori Zaremba, RN.

University of Pennsylvania, Philadelphia, Pa., USA: Larry Kaiser, MD (Principal Investigator); John Hansen-Flaschen, MD (Co-Principal Investigator); Mary Louise Dempsey, BSN, RN
(Principal Clinic Coordinator); Abass Alavi, MD; Theresa Alcorn, Selim Arcasoy, MD; Judith Aronchick, MD; Stanley Aukberg, MD; Bryan Benedict, RRT; Susan Craemer, BS, RRT, CPFT; Ron Daniele, MD; Jeffrey Edelman, MD; Warren Gefter, MD; Laura Kotler-Klein, MSS; Robert Kotloff, MD; David Lipson, MD; Wallace Miller Jr, MD; Richard O'Connell, RPFT; Staci Opelman, MSW; Harold Palevsky, MD; William Russell, RPFT; Heather Sheaffer, MSW; Rodney Simcox, BSRT, RRT; Susanne Snedeker, RRT, CPFT; Jennifer Stone-Wynne, MSW; Gregory Tino, MD; Peter Wahl; James Walter, RPFT; Patricia Ward; David Zisman, MD; James Mendez, MSN, CRNP (1997-2001); Angela Wurster, MSN, CRNP (1997-1999).

University of Pittsburgh, Pittsburgh, Pa., USA: Frank Sciurba, MD (Principal Investigator); James Luketich, MD (Co-Principal Investigator); Colleen Witt, MS (Principal Clinic Coordinator); Gerald Ayres; Michael Donahoe, MD; Carl Fuhrman, MD; Robert Hoffman, MD; Joan Lacomis, MD; Joan Sexton; William Slivka; Diane Strollo, MD; Erin Sullivan, MD; Tomeka Simon; Catherine Wrona, RN, BSN; Gerene Bauldoff, RN, MSN (1997-2000); Manuel Brown, MD (1997-2002); Elisabeth George, RN, MSN (Principal Clinic Coordinator 1997-2001); Robert Keenan, MD (Co-Principal Investigator 1997-2000); Theodore Kopp, MS (1997-1999); Laurie Silfies (1997-2001).

University of Washington, Seattle, Wash., USA: Joshua Benditt, MD (Principal Investigator), Douglas Wood, MD (Co-Principal Investigator); Margaret Snyder, MN (Principal Clinic Coordinator); Kymberley Anable; Nancy Battaglia; Louie Boitano; Andrew Bowdle, MD; Leighton Chan, MD; Cindy Chwalik; Bruce Culver, MD; Thurman Gillespy, MD; David Godwin, MD; Jeanne Hoffman; Andra Ibrahim, MD; Diane Lockhart; Stephen Marglin, MD; Kenneth Martay, MD; Patricia McDowell; Donald Oxorn, MD; Liz Roessler; Michelle Toshima; Susan Golden (1998-2000).

\section{Other Participants}

Agency for Healthcare Research and Quality, Rockville, Md., USA: Lynn Bosco, MD, MPH; Yen-Pin Chiang, PhD; Carolyn Clancy, MD; Harry Handelsman, DO.

Centers for Medicare and Medicaid Services, Baltimore, Md., USA: Steven M Berkowitz, PhD; Tanisha Carino, PhD; Joe Chin, MD; JoAnna Baldwin; Karen McVearry; Anthony Norris; Sarah Shirey; Claudette Sikora Steven Sheingold, PhD (1997-2004).

Coordinating Center, The Johns Hopkins University, Baltimore, Md., USA: Steven Piantadosi, MD, PhD (Principal Investigator); James Tonascia, $\mathrm{PhD}$ (Co-Principal Investigator); Patricia Belt; Amanda Blackford, ScM; Karen Collins; Betty Collison; Ryan Colvin, MPH; John Dodge; Michele Donithan, MHS; Vera Edmonds; Gregory L. Foster, MA; Julie Fuller; Judith Harle; Rosetta Jackson; Shing Lee, ScM; Charlene Levine; Hope Livingston; Jill Meinert; Jennifer Meyers; Deborah Nowakowski; Kapreena Owens; Shangqian Qi, MD; Michael Smith; Brett Simon, MD; Paul Smith; Alice Sternberg, ScM; Mark Van Natta, MHS; Laura Wilson, ScM; Robert Wise, MD.

Cost Effectiveness Subcommittee: Robert M. Kaplan, $\mathrm{PhD}$ (Chair); J. Sanford Schwartz, MD (Co-Chair); Yen-Pin Chiang, PhD; Marianne C. Fahs, PhD; A. Mark Fendrick, MD; Alan J. Moskowitz, MD; Dev Pathak, PhD; Scott Ramsey, MD, PhD; Steven Sheingold, PhD; A. Laurie Shroyer, PhD; Judith Wagner, PhD; Roger Yusen, MD.

Cost Effectiveness Data Center, Fred Hutchinson Cancer Research Center, Seattle, Wash., USA: Scott Ramsey, MD, PhD (Prin- 
cipal Investigator); Ruth Etzioni, $\mathrm{PhD}$; Sean Sullivan, $\mathrm{PhD}$; Douglas Wood, MD; Thomas Schroeder, MA; Karma Kreizenbeck; Kristin Berry, MS; Nadia Howlader, MS.

CT Scan Image Storage and Analysis Center, University of Iowa, Iowa City, Iowa, USA: Eric Hoffman, PhD (Principal Investigator); Janice Cook-Granroth, BS; Angela Delsing, RT; Junfeng Guo, PhD; Geoffrey McLennan, MD; Brian Mullan, MD; Chris Piker, BS; Joseph Reinhardt, PhD; Blake Wood; Jered Sieren, RTR; William Stanford, MD.

Data and Safety Monitoring Board: John A. Waldhausen, MD (Chair); Gordon Bernard, MD; David DeMets, PhD; Mark Ferguson, MD; Eddie Hoover, MD; Robert Levine, MD; Donald Mahler, $\mathrm{MD}$; A. John McSweeny, PhD; Jeanine Wiener-Kronish, MD; O. Dale Williams, PhD; Magdy Younes, MD.

Marketing Center, Temple University, Philadelphia, Pa., USA: Gerard Criner, MD (Principal Investigator); Charles Soltoff, MBA. Project Office, National Heart, Lung, and Blood Institute, Bethesda, Md., USA: Gail Weinmann, MD (Project Officer); Joanne Deshler (Contracting Officer); Dean Follmann, PhD; James Kiley, PhD; Margaret Wu, PhD (1996-2001).

\section{Acknowledgments}

R.B. is supported by grant 1K23CA106544 from the National Institutes of Health. The National Emphysema Treatment Trial (NETT) is supported by contracts with the National Heart, Lung, and Blood Institute (N01HR76101, N01HR76102, N01HR76103, N01HR76104, N01HR76105, N01HR76106, N01HR76107, N01HR76108, N01HR76109, N01HR76110, N01HR76111, N01HR76112, N01HR76113, N01HR76114, N01HR76115, N01HR76116, N01HR76118, and N01HR76119), the Centers for Medicare and Medicaid Services (CMS; formerly the Health Care Financing Administration); and the Agency for Healthcare Research and Quality.

\section{References}

1 Mapel DW, Hurley JS, Frost FJ, Petersen HV, Picchi MA, Coultas DB: Health care utilization in chronic obstructive pulmonary disease. A case-control study in a health maintenance organization. Arch Intern Med 2000;160:2653-2658.

2 Jemal A, Ward E, Hao Y, Thun M: Trends in the leading causes of death in the United States, 1970-2002. JAMA 2005;294:12551259.

-3 Morgan MD: Preventing hospital admissions for COPD: role of physical activity. Thorax 2003;58:95-96.

-4 Donaldson GC, Seemungal TA, Bhowmik A, Wedzicha JA: Relationship between exacerbation frequency and lung function decline in chronic obstructive pulmonary disease. Thorax 2002;57:847-852.

5 Spencer S, Jones PW: Time course of recovery of health status following an infective exacerbation of chronic bronchitis. Thorax 2003;58:589-593.

6 Almagro P, Calbo E, Ochoa de Echaguen A, Barreiro B, Quintana S, Heredia JL, Garau J: Mortality after hospitalization for COPD. Chest 2002;121:1441-1448.

7 Garcia-Aymerich J, Lange P, Benet M, Schnohr P, Anto JM: Regular physical activity reduces hospital admission and mortality in chronic obstructive pulmonary disease: a population-based cohort study. Thorax 2006;61:772-778.

8 Garcia-Aymerich J, Lange P, Benet M, Schnohr P, Anto JM: Regular physical activity modifies smoking-related lung function decline and reduces risk of chronic obstructive pulmonary disease: a population-based cohort study. Am J Respir Crit Care Med 2007; 175:458-463.
Gudmundsson G, Gislason T, Janson C, 15 Naunheim KS, Wood DE, Mohsenifar Z, Lindberg E, Hallin R, Ulrik CS, Brondum E, Nieminen MM, Aine T, Bakke P: Risk factors for rehospitalisation in COPD: role of health status, anxiety and depression. Eur Respir J 2005;26:414-419.

10 DeSalvo KB, Fan VS, McDonell MB, Fihn SD: Predicting mortality and healthcare utilization with a single question. Health Serv Res 2005;40:1234-1246.

11 Fan VS, Curtis JR, Tu SP, McDonell MB, Fihn SD: Using quality of life to predict hospitalization and mortality in patients with obstructive lung diseases. Chest 2002;122: 429-436.

12 Almagro P, Barreiro B, Ochoa de Echaguen A, Quintana S, Rodriguez Carballeira M, Heredia JL, Garau J: Risk factors for hospital readmission in patients with chronic obstructive pulmonary disease. Respiration 2006;73:311-317.

13 Fishman A, Martinez F, Naunheim K, Piantadosi S, Wise R, Ries A, Weinmann G, Wood DE: A randomized trial comparing lung-volume-reduction surgery with medical therapy for severe emphysema. N Engl J Med 2003;348:2059-2073.

14 Martinez FJ, Foster G, Curtis JL, Criner G, Weinmann G, Fishman A, DeCamp MM, Benditt J, Sciurba F, Make B, Mohsenifar Z, Diaz P, Hoffman E, Wise R: Predictors of mortality in patients with emphysema and severe airflow obstruction. Am J Respir Crit Care Med 2006;173:1326-1334. Sternberg AL, Criner GJ, DeCamp MM, Deschamps CC, Martinez FJ, Sciurba FC, Tonascia J, Fishman AP: Long-term followup of patients receiving lung-volume-reduction surgery versus medical therapy for severe emphysema by the National Emphysema Treatment Trial Research Group. Ann Thorac Surg 2006;82:431-443.

16 Beck AT, Epstein N, Brown G, Steer RA: An inventory for measuring clinical anxiety: psychometric properties. J Consult Clin Psychol 1988;56:893-897.

17 Whooley MA, Avins AL, Miranda J, Browner WS: Case-finding instruments for depression. Two questions are as good as many. J Gen Intern Med 1997;12:439-445.

18 Burg MM, Benedetto MC, Soufer R: Depressive symptoms and mortality two years after coronary artery bypass graft surgery (CABG) in men. Psychosom Med 2003;65:508-510.

19 Connerney I, Shapiro PA, McLaughlin JS, Bagiella E, Sloan RP: Relation between depression after coronary artery bypass surgery and 12-month outcome: a prospective study. Lancet 2001;358:1766-1771.

20 Spertus JA, Jones P, McDonell M, Fan V, Fihn SD: Health status predicts long-term outcome in outpatients with coronary disease. Circulation 2002;106:43-49.

21 Fan VS, Ramsey SD, Giardino ND, Make BJ, Emery CF, Diaz PT, Benditt JO, Mosenifar Z, McKenna R Jr, Curtis JL, Fishman AP, Martinez FJ: Sex, depression, and risk of hospitalization and mortality in chronic obstructive pulmonary disease. Arch Intern Med 2007; 167:2345-2353. 
22 Hokanson JM, Anderson RL, Hennrikus DJ, Lando HA, Kendall DM: Integrated tobacco cessation counseling in a diabetes self-management training program: a randomized trial of diabetes and reduction of tobacco. Diabetes Educ 2006;32:562-570.

$>23$ Wolf AM, Siadaty M, Yaeger B, Conaway MR, Crowther JQ, Nadler JL, Bovbjerg VE: Effects of lifestyle intervention on health care costs: Improving control with activity and nutrition (ICAN). J Am Diet Assoc 2007; 107:1365-1373.

24 Burke BL, Arkowitz H, Menchola M: The efficacy of motivational interviewing: a metaanalysis of controlled clinical trials. J Consult Clin Psychol 2003;71:843-861.
25 Celli BR, Cote CG, Marin JM, Casanova C, Montes de Oca M, Mendez RA, Pinto Plata V, Cabral HJ: The body-mass index, airflow obstruction, dyspnea, and exercise capacity index in chronic obstructive pulmonary disease. N Engl J Med 2004;350:1005-1012.

26 Soler-Cataluna JJ, Martinez-Garcia MA, Sanchez LS, Tordera MP, Sanchez PR: Severe exacerbations and BODE index: two independent risk factors for death in male COPD patients. Respir Med 2009;103:692-699.

27 Ong KC, Earnest A, Lu SJ: A multidimensional grading system (BODE index) as predictor of hospitalization for COPD. Chest 2005;128:3810-3816.

28 Wedzicha JA, Seemungal TA: COPD exacerbations: defining their cause and prevention. Lancet 2007;370:786-796.
29 Bourbeau J, Julien M, Maltais F, Rouleau M, Beaupré A, Begin R, Renzi P, Nault D, Borycki E, Schwartzman K, Singh R, Collet JP: Reduction of hospital utilization in patients with chronic obstructive pulmonary disease: a disease-specific self-management intervention. Arch Intern Med 2003;163:585-591.

30 Casas A, Troosters T, Garcia-Aymerich J, Roca J, Hernandez C, Alonso A, del Pozo F, de Toledo P, Anto JM, Rodriguez-Roisin R, Decramer M: Integrated care prevents hospitalisations for exacerbations in COPD patients. Eur Respir J 2006;28:123-130.

31 Osthoff M, Leuppi JD: Management of chronic obstructive pulmonary disease patients after hospitalization for acute exacerbation. Respiration 2010;79:255-261. 
